\title{
Weight management and determinants of weight change in patients with coronary artery disease
}

\author{
Arno Tijssen, ${ }^{1}$ Marjolein Snaterse ${ }^{0},{ }^{1}$ Madelon Minneboo, ${ }^{2}$ Sangeeta Lachman, ${ }^{2}$ \\ Wilma Scholte op Reimer, ${ }^{2,3}$ Ron J Peters, ${ }^{2}$ Harald Thune Jørstad ${ }^{2}$
}

\begin{abstract}
- Additional supplemental material is published online only. To view, please visit the journal online (http://dx.doi. org/10.1136/heartjnl-2021319224).
\end{abstract}

${ }^{1}$ Centre of Expertise, Faculty of Health, Amsterdam University of Applied Sciences, Amsterdam, Noord-Holland, The Netherlands ${ }^{2}$ Department of Cardiology, Amsterdam UMC, University of Amsterdam, Amsterdam, NoordHolland, The Netherlands ${ }^{3}$ Research Group Chronic Diseases, HU University of Applied Sciences Utrecht, Utrecht, The Netherlands

\section{Correspondence to}

Mrs Marjolein Snaterse, Centre of Expertise, Faculty of Health, Amsterdam University of Applied Sciences, Amsterdam, Noord-Holland, Netherlands; m.snaterse@hva.nl

Received 20 February 2021 Accepted 28 June 2021 Published Online First 29 July 2021

\section{SLinked}

- http://dx.doi.org/10.1136/ heartjnl-2021-319726

Check for updates

(C) Author(s) (or their employer(s)) 2021. No commercial re-use. See rights and permissions. Published by BMJ.

To cite: Tijssen $A$,

Snaterse M,

Minneboo $M$, et al. Heart

2021:107:1552-1559.

\section{ABSTRACT}

Objective To study the effects of a comprehensive secondary prevention programme on weight loss and to identify determinants of weight change in patients with coronary artery disease (CAD).

Methods We performed a secondary analysis focusing on the subgroup of overweight CAD patients $\left(\mathrm{BMI} \geq 27 \mathrm{~kg} / \mathrm{m}^{2}\right)$ in the Randomised Evaluation of Secondary Prevention by Outpatient Nurse SpEcialists-2 (RESPONSE-2) multicentre randomised trial. We evaluated weight change from baseline to 12-month follow-up; multivariable logistic regression with backward elimination was used to identify determinants of weight change.

Results Intervention patients $(n=280)$ lost significantly more weight than control patients $(n=257)(-2.4 \pm 7.1$ $\mathrm{kg}$ vs $-0.2 \pm 4.6 \mathrm{~kg} ; \mathrm{p}<0.001)$. Individual weight change varied widely, with weight gain $(\geq 1.0 \mathrm{~kg})$ occurring in $36 \%$ of interventions versus $41 \%$ controls $(p=0.21)$. In the intervention group, weight loss of $\geq 5 \%$ was associated with higher age (OR 2.94), lower educational level (OR 1.91), non-smoking status (OR 2.92), motivation to start with weight loss directly after the baseline visit (OR 2.31) and weight loss programme participation (OR 3.33), whereas weight gain ( $\geq 1 \mathrm{~kg})$ was associated with smoking cessation $\leq 6$ months before or during hospitalisation (OR 3.21), nonCaucasian ethnicity (OR 2.77), smoking at baseline (OR $2.70)$, lower age ( $<65$ years) (OR 1.47) and weight loss programme participation (OR 0.59).

Conclusion The comprehensive secondary prevention programme was, on average, effective in achieving weight loss. However, wide variation was observed. As weight gain was observed in over one in three participants in both groups, prevention of weight gain may be as important as attempts to lose weight. Trial registration number NTR3937.

\section{INTRODUCTION}

Overweight is a global health problem and highly prevalent $(70 \%-80 \%)$ in patients with established cardiovascular disease (CVD). ${ }^{1}$ Weight loss interventions have been shown to achieve meaningful weight loss of $5 \%-10 \%$, which is associated with a clinically significant reduction of CVD risk. ${ }^{2}$ Few such interventions, however, can be delivered on a large scale. ${ }^{4}$

In the setting of primary prevention, referral to a commercial weight loss programme (Weight Watchers) has been demonstrated to be effective in achieving meaningful weight loss. ${ }^{5}$ An advantage of such a commercial intervention is that it is widely available in many countries at low cost. We recently investigated this weight loss programme as part of a comprehensive secondary prevention strategy in the Randomised Evaluation of Secondary Prevention by Outpatient Nurse-SpEcialists-2 (RESPONSE-2) trial. We found that in patients with coronary artery disease (CAD), a combination of nursecoordinated care and referral to up to three widely available community-based lifestyle programmes, on top of usual care, is significantly more effective in improving at least one lifestyle-related risk factor (LRF) when compared with usual care alone. ${ }^{6}$ The lifestyle programmes addressed weight reduction (Weight Watchers), promoting physical activity (Philips DirectLife) and smoking cessation (Luchtsignaal), and referral was dependent on the patients' risk profile and preferences. The difference in the primary outcome was mainly driven by improvements in weight reduction.

In this secondary analysis, we aimed to rigorously evaluate the effects of referral to the comprehensive intervention on weight change and to identify determinants associated with weight change.

\section{METHODS}

\section{Study design}

We used data on a subgroup of overweight CAD patients (body mass index (BMI) $\geq 27 \mathrm{~kg} / \mathrm{m}^{2}$ ) from the RESPONSE-2 trial, a multicentre randomised controlled trial conducted in the Netherlands. Study methods and main results have been published and are summarised further. ${ }^{67}$

\section{Patient population}

Eligible patients had been hospitalised for CAD and/or underwent revascularisation. For the main trial, we included patients with at least one of three LRFs: (1) smoking at baseline or stopped $\leq 6$ months before hospitalisation, (2) overweight $\left(\right.$ BMI $\geq 27 \mathrm{~kg} / \mathrm{m}^{2}$ ) and (3) self-reported physical inactivity ( $\leq 150 \mathrm{~min}$ of moderate intensity physical activity per week) and were willing to attend any of the lifestyle programmes. The current analysis excluded patients with a $\mathrm{BMI}<27 \mathrm{~kg} / \mathrm{m}^{2}$, as the study protocol allowed only individuals with a $\mathrm{BMI} \geq 27 \mathrm{~kg} / \mathrm{m}^{2}$ for participation in the weight loss programme.

\section{Usual care}

All patients received usual care. This included visits to the cardiologist and/or other specialists, cardiac 
rehabilitation and up to four visits to a nurse-led secondary prevention programme. Cardiac rehabilitation consisted of up to 12 weeks of outpatient physical rehabilitation and counselling on secondary prevention, work resumption and psychological support. The nurse-led secondary prevention programme addressed healthy lifestyles, drug-treated risk factors and medication adherence, according to national and international guidelines. ${ }^{8-10}$ We encouraged patients to bring their partners to counselling sessions.

\section{Intervention}

In addition to usual care, patients and their partners in the intervention group were offered free participation in up to three community-based lifestyle programmes to achieve weight reduction (Weight Watchers), increase physical activity levels (Philips DirectLife) and smoking cessation (Luchtsignaal). Specifics of the lifestyle programmes have been described previously and are outlined in the online appendix. ${ }^{7}$ Patient preferences were leading in the choice of programme(s), the number of programmes followed and the sequence and duration. Programmes were offered unmodified, as they were available in the community.

\section{Patient and public involvement}

RESPONSE-2 was developed based on experiences with RESPONSE-1 including an evaluation study involving patients and nurses. ${ }^{11}$ Results from the main paper have been distributed among patients and nurses.

\section{Data collection and measurements}

Nurses collected demographic and medical data at baseline (first outpatient clinic visit $\leq 8$ weeks after hospital discharge) and at 12-month follow-up. Patients' motivation towards lifestyle change ('motivated'/'not motivated') was assessed with motivational interviewing during each outpatient clinic visit. Subsequently, for interventions, motivation was ranked as 'motivated for short-term ( $<1$ month) lifestyle improvement' or 'ambivalent'. Weight was measured in light clothes without shoes using bioimpedance scales. Physical activity level was assessed through self-report based on WHO recommendations and by completing a 6 min walking distance (6MWD) test. ${ }^{12}{ }^{13}$ Smoking status was assessed by self-report and by urinary-cotinine test (UltiMed one step; Dutch Diagnostic, Zutphen, The Netherlands; detection limit $200 \mathrm{ng} / \mathrm{mL}$ ). Weight change from baseline to 12 -month follow-up was categorised in three groups: weight gain $(\geq 1$ $\mathrm{kg}$ ), unchanged (weight change $<1 \mathrm{~kg}$ ) and weight loss $(\geq 1$ $\mathrm{kg})$. Successful weight loss was defined according to the European Society of Cardiology (ESC) prevention guidelines as $\geq 5 \%$ reduction of weight compared with baseline.

\section{Outcomes}

The primary outcome was weight change from baseline to 12-month follow-up. Secondary outcomes were changes in body composition (body fat percentage and waist circumference), changes in associated CVD risk factors (blood pressure, lipids, glucose and glycated haemoglobin levels) and achievement of LRF targets $(\geq 5 \%$ weight loss, $\geq 10 \%$ increase in $6 \mathrm{MWD}$ and smoking cessation).

\section{Statistical methods}

We analysed patients according to intention to treat, irrespective of attendance to the lifestyle interventions. Loss to follow-up was assessed following the methods proposed by Carpenter and Kenward. $^{14}$
The primary analysis compared the mean weight change from baseline to 12-month follow-up in intervention and control patients. Comparisons between groups were made by linear or logistic regression analysis, independent samples t-tests and Fisher's exact tests, as appropriate. To assess the stability of weight change and change in CVD risk factors, we performed a sensitivity analysis adjusted for covariates that were used to stratify the randomisation, covariates that were part of the loss to follow-up mechanism and education level, which was unbalanced at baseline. ${ }^{6}$

We used stepwise regression with backward elimination $(p<0.157)$ to identify determinants of successful weight loss and of weight gain. ${ }^{15}$ Covariates included in the backward elimination procedures were selected a priori based on literature and expert knowledge. The models were estimated in 20 imputed datasets and regression coefficients, and $\mathrm{p}$ values were pooled using Rubin's rule. The models were validated in 250 bootstrap samples drawn from the original data with missing values and missing values filled in by multiple imputation $(\mathrm{m}=20)$ in each bootstrap sample. ${ }^{16} \mathrm{~A}$ full description of the analyses is presented in the online appendix. Because several covariates were not available for control patients, we included only intervention group patients in the analyses.

Finally, all determinant-outcome associations were assessed for interaction with treatment allocation $(p<0.05)$ to identify patients on whom the intervention impacted significantly. All statistical tests were two tailed, and a p value of $<0.05$ was used to indicate statistical significance. Analyses were performed using R-studio, V.3.6.1.

\section{RESULTS}

In total, 824 patients provided informed consent and were randomised, of whom 609 patients had a BMI $\geq 27 \mathrm{~kg} / \mathrm{m}^{2}$. After 12 months, 537 (88\%) patients attended the follow-up visit and were included in the current analysis (figure 1). Patients attending the 12-month follow-up had a mean age of 59.1 ( \pm 9.1$)$ years, $23 \%$ were women and $83 \%$ were living with a partner (table 1 ). The majority of patients (64\%) had no previous history of CVD. In total, $42 \%$ of patients smoked during the 6 months preceding hospitalisation, mean body mass index (BMI) was $31 \mathrm{~kg} / \mathrm{m}^{2}$ and $61 \%$ of patients did not meet the criterion for adequate physical activity. At baseline, the use of preventive medication was high, and most patients (90\%) attended cardiac rehabilitation.

Compared with those who completed the 12-month follow-up visit, patients lost to follow-up were more often controls, of lower age, smoking at baseline and had at baseline a slightly higher systolic blood pressure (area under curve (AUC) 0.68). We found no evidence of differential loss to follow-up between treatment arms (online appendix, table $1 \mathrm{a}$ and $1 \mathrm{~b}$ ).

In the intervention group, a total of 182 patients (65\%) participated in the weight loss programme. Patients attended a median of 12 (range 0-50) meetings, and 81 patients (43\%) were joined by their partners. The number of meetings was positively associated with the mean change in weight $(\mathrm{p}<0.001)$ (online appendix, figure 1). Patient motivation, programme attendance and partner participation in patients with and without successful weight loss are shown in the online appendix table 2.

At 12-month follow-up, patients in the intervention group had lost significantly more weight than those in the control group (average $-2.4 \pm 7.1 \mathrm{~kg}$ vs $-0.2 \pm 4.6 \mathrm{~kg}, \mathrm{p}<0.001$ ) (table 2 ). Similar results were seen for decreases in waist circumference $(-3.7 \pm 6.8 \mathrm{~cm}$ in interventions vs $-1.9 \pm 5.4 \mathrm{~cm}$ in controls; $\mathrm{p}<0.001)$ and body fat percentage $(-1.2 \% \pm 7.3$ in interventions 


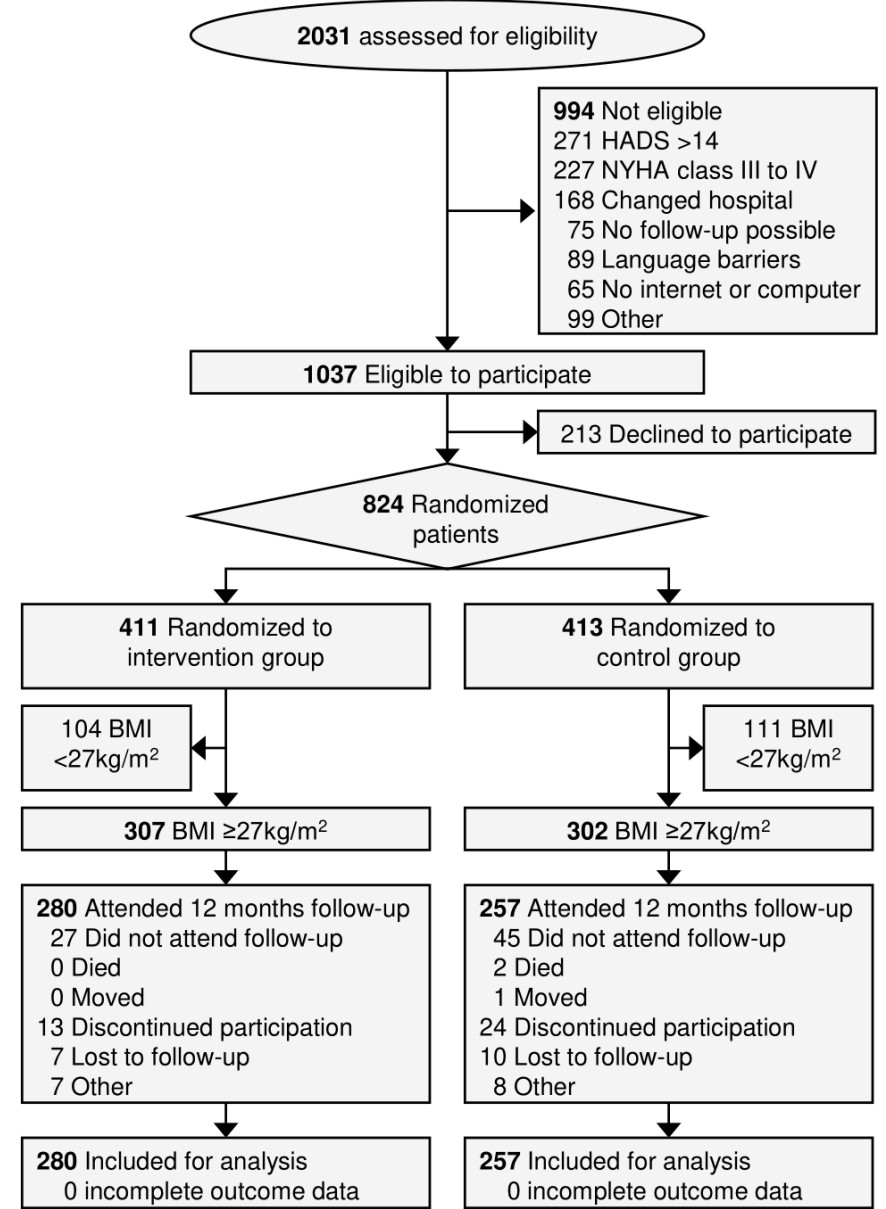

Figure 1 Study flow chart.

vs. $+0.3 \% \pm 6.5$ in controls; $\mathrm{p}=0.02$ ). Improvements in body weight and waist circumference were greater in patients who had attended the weight loss programme. These findings were stable for adjustments as described in the sensitivity analysis (online appendix table 3 ).

Successful weight loss was observed more frequently in the intervention group than in controls $(32 \%$ vs $16 \% ; \mathrm{p}<0.001)$ (online appendix, table 4). Four per cent of patients in the intervention group achieved a BMI of $\leq 25 \mathrm{~kg} / \mathrm{m}^{2}$ compared with none in the control group $(\mathrm{p}=0.002)$. Moreover, patients in the intervention group who smoked at baseline quit more frequently than controls $(30 \%$ vs $11 \% ; \mathrm{p}<0.05)$. Mean weight gain among patients who had quit smoking at 12-month follow-up was 0.9 $\mathrm{kg}( \pm 7.4)$ in the intervention group and $1.8 \mathrm{~kg}( \pm 5.2)$ in the control group $(\mathrm{p}=0.45)$.

Observed weight change varied widely between individual patients, as shown in the waterfall plots (figure 2). Weight change in the intervention group ranged from $+23 \mathrm{~kg}$ to -25 $\mathrm{kg}$ and from $+13 \mathrm{~kg}$ to $-15 \mathrm{~kg}$ in the control group. A considerable number of patients gained weight $(\geq 1.0 \mathrm{~kg}): 36 \%$ and $41 \%$ $(\mathrm{p}=0.21)$ in the intervention and control group, respectively (mean $+4.4 \pm 3.3 \mathrm{~kg}$ vs $+4.0 \pm 2.5 \mathrm{~kg} ; \mathrm{p}=0.33$ ). Evaluation of weight change per baseline LRF group demonstrated that in the intervention group, patients with overweight only and patients with overweight and inadequate physical activity lost substantially more weight compared with controls $(-4.7 \mathrm{~kg}$ vs $-1.0 \mathrm{~kg}$; $\mathrm{p}<0.001$ and $-4.4 \mathrm{~kg}$ vs $-0.1 \mathrm{~kg} ; \mathrm{p}<0.001$ ) (table 3).

Stepwise regression with backward elimination identified five determinants associated with successful weight loss in
Table 1 Baseline characteristics

\begin{tabular}{|c|c|c|}
\hline & $\begin{array}{l}\text { Intervention group } \\
(\mathrm{n}=280)\end{array}$ & $\begin{array}{l}\text { Control group } \\
(n=257)\end{array}$ \\
\hline \multicolumn{3}{|l|}{ Demographics (\%) } \\
\hline Age (years) & $58.6 \pm 9.0$ & $59.7 \pm 9.2$ \\
\hline Sex (female) & $65(23.2)$ & $57(22.2)$ \\
\hline Ethnicity (Caucasian) & $264(94.3)$ & $238(92.6)$ \\
\hline Education (higher)* & $105(37.5)$ & $68(26.5)$ \\
\hline Partner & $234(83.6)$ & $211(82.1)$ \\
\hline \multicolumn{3}{|l|}{ Index event (\%) } \\
\hline STEMI & $114(40.7)$ & $98(38.1)$ \\
\hline NSTEMI & $103(36.8)$ & $88(34.2)$ \\
\hline Unstable AP & $26(9.3)$ & $26(10.1)$ \\
\hline Stable angina revascularisation & $37(13.2)$ & $45(17.5)$ \\
\hline \multicolumn{3}{|l|}{ Treatment index event (\%) } \\
\hline $\mathrm{PCl}$ & $214(76.4)$ & $202(78.6)$ \\
\hline CABG & $29(10.4)$ & $30(11.7)$ \\
\hline Medication only & $37(13.2)$ & $25(9.7)$ \\
\hline \multicolumn{3}{|l|}{ Previous CVD (\%) } \\
\hline Myocardial infarction & $58(20.7)$ & $65(25.3)$ \\
\hline Percutaneous coronary intervention & $45(16.1)$ & $44(17.1)$ \\
\hline Coronary artery bypass surgery & $15(5.4)$ & $10(3.9)$ \\
\hline Stroke & $5(1.8)$ & $9(3.5)$ \\
\hline Peripheral artery disease & $18(6.4)$ & $11(4.3)$ \\
\hline No known previous CVD & $184(65.7)$ & $157(61.1)$ \\
\hline \multicolumn{3}{|l|}{ CVD risk factors (\%) } \\
\hline Diabetes mellitus & $48(17.1)$ & $47(18.3)$ \\
\hline History of hypertension & $108(38.6)$ & $115(44.7)$ \\
\hline History of dyslipidaemia & $73(26.1)$ & $67(26.1)$ \\
\hline \multicolumn{3}{|l|}{ Smoking } \\
\hline Pre-event smokingt & $122(43.6)$ & $104(40.5)$ \\
\hline Smoking at baselineł & 39 (13.9) & $45(17.5)$ \\
\hline Inadequate physical activity§ & $108(38.6)$ & $101(39.3)$ \\
\hline \multicolumn{3}{|l|}{ BMI category } \\
\hline$\geq 27-<30 \mathrm{~kg} / \mathrm{m}^{2}$ & $109(38.9)$ & $118(45.9)$ \\
\hline$\geq 30-<35 \mathrm{~kg} / \mathrm{m}^{2}$ & $126(45.0)$ & $100(38.9)$ \\
\hline$\geq 35-<40 \mathrm{~kg} / \mathrm{m}^{2}$ & $37(13.2)$ & $31(12.1)$ \\
\hline$\geq 40 \mathrm{~kg} / \mathrm{m}^{2}$ & $8(2.9)$ & $8(3.1)$ \\
\hline \multicolumn{3}{|l|}{ Lifestyle-related risk factor groups (\%) } \\
\hline $\mathrm{BMl} \geq 27 \mathrm{~kg} / \mathrm{m}^{2}$ only & $65(23.2)$ & $63(24.5)$ \\
\hline $\begin{array}{l}\mathrm{BMI} \geq 27 \mathrm{~kg} / \mathrm{m}^{2} \text { and inadequate physical } \\
\text { activity }\end{array}$ & $93(33.2)$ & $90(35.0)$ \\
\hline $\mathrm{BMI} \geq 27 \mathrm{~kg} / \mathrm{m}^{2}$ and smoking & $43(15.4)$ & $38(14.8)$ \\
\hline $\begin{array}{l}\mathrm{BMI} \geq 27 \mathrm{~kg} / \mathrm{m}^{2} \text {, inadequate physical } \\
\text { activity and smoking }\end{array}$ & $66(25.7)$ & $79(28.2)$ \\
\hline \multicolumn{3}{|l|}{ Medication (\%) } \\
\hline Antiplatelet & $278(99.3)$ & $250(97.3)$ \\
\hline$\beta$-blockers & $234(83.6)$ & $227(88.3)$ \\
\hline ACE inhibiter/ARB & $220(78.6)$ & $185(72.0)$ \\
\hline Lipid-lowering drugs & $271(96.8)$ & $250(97.3)$ \\
\hline
\end{tabular}

Values presented as mean \pm SD and counts (\%)

*Higher education: universities of applied sciences and research universities.

tSmoking $\leq 6$ months before hospital admission.

$\ddagger$ Baseline urine-cotinine level $>200 \mathrm{ng} / \mathrm{mL}$.

$\S$ Self-reported based on WHO recommendations.

$A P$, angina pectoris; $A R B$, angiotensin II-receptor blocker; $B M I$, body mass index; $C A B G$, coronary artery bypass grafting; CVD, cardiovascular disease; NSTEMI, non-ST-elevation myocardial infarction; $\mathrm{PCl}$, percutaneous coronary intervention; STEMI, ST-elevation myocardial infarction.

the intervention group $(\mathrm{n}=280)$ : higher age ( $\geq 65$ years) (OR 2.94), lower educational level (OR 1.91), non-smoking status (defined as never smoking or quit $\leq 6$ months before hospitalisation; OR 2.92), being motivated to start the weight loss 
Table 2 Outcome data at 12-month follow-up in patients with baseline BMI $\geq 27 \mathrm{~kg} / \mathrm{m}^{2}$

\begin{tabular}{|c|c|c|c|c|c|c|c|}
\hline & \multicolumn{2}{|l|}{ Baseline } & \multicolumn{2}{|c|}{ Change at 12 months } & \multirow[b]{2}{*}{ Between group difference, mean $(95 \% \mathrm{Cl})$} & \multirow[b]{2}{*}{$P$ value } & \multirow[b]{2}{*}{$\begin{array}{l}\text { WW participants } \\
(n=182)\end{array}$} \\
\hline & $\begin{array}{l}\text { Intervention } \\
(\mathrm{n}=280)\end{array}$ & $\begin{array}{l}\text { Control } \\
(n=257)\end{array}$ & $\begin{array}{l}\text { Intervention } \\
(\mathrm{n}=280)\end{array}$ & $\begin{array}{l}\text { Control } \\
(n=257)\end{array}$ & & & \\
\hline \multicolumn{8}{|l|}{ Primary outcomes } \\
\hline Body weight, $\mathrm{kg}$ & $97.8 \pm 13.7$ & $96.6 \pm 14.2$ & $-2.4 \pm 7.1$ & $-0.2 \pm 4.6$ & $-2.2(-3.2$ to -1.2$)$ & $<0.001$ & $-3.6 \pm 7.6$ \\
\hline $\mathrm{BMI}, \mathrm{kg} / \mathrm{m}^{2}$ & $31.7 \pm 3.6$ & $31.2 \pm 3.5$ & $-0.8 \pm 2.3$ & $-0.1 \pm 1.5$ & $-0.7(-1.1$ to -0.4$)$ & $<0.001$ & $-1.2 \pm 2.5$ \\
\hline \multicolumn{8}{|l|}{ Secondary outcomes } \\
\hline Body fat percentage, $\%$ & $33.5 \pm 8.5$ & $32.3 \pm 8.7$ & $-1.2 \pm 7.3$ & $0.3 \pm 6.5$ & $-1.6(-2.9$ to -0.3$)$ & $<0.05$ & $-1.3 \pm 7.5$ \\
\hline Waist circumference, $\mathrm{cm}$ & $111.6 \pm 10.1$ & $110 \pm 10.2$ & $-3.7 \pm 6.8$ & $-1.9 \pm 5.4$ & $-2.0(-3.1$ to -1.0$)$ & $<0.001$ & $-4.9 \pm 7.3$ \\
\hline \multicolumn{8}{|l|}{ Blood pressure, mm Hg } \\
\hline Systolic & $134 \pm 18.4$ & $135 \pm 17.5$ & $-2.1 \pm 19.0$ & $1.9 \pm 18.6$ & $-4.1(-7.3$ to -0.9$)$ & $<0.05$ & $-2.5 \pm 18.6$ \\
\hline Diastolic & $79 \pm 9.6$ & $79 \pm 10.3$ & $-0.3 \pm 10.9$ & $1.9 \pm 11.6$ & $-2.1(-4.0$ to -0.2$)$ & $<0.05$ & $-0.3 \pm 11.3$ \\
\hline \multicolumn{8}{|l|}{ Cholesterol, mmol/L } \\
\hline Total cholesterol & $4.1 \pm 0.9$ & $4.1 \pm 1.2$ & $-0.03 \pm 0.94$ & $-0.07 \pm 1.24$ & $0.04(-0.15$ to -0.23$)$ & 0.67 & $-0.03 \pm 0.87$ \\
\hline LDL-C & $2.2 \pm 0.8$ & $2.2 \pm 0.8$ & $0.01 \pm 0.85$ & $-0.01 \pm 0.90$ & $0.03(-0.12$ to 0.18$)$ & 0.68 & $-0.02 \pm 0.78$ \\
\hline $\mathrm{HDL}-\mathrm{C}$ & $1.1 \pm 0.4$ & $1.2 \pm 0.4$ & $0.06 \pm 0.34$ & $0.04 \pm 0.33$ & $0.02(-0.04$ to 0.08$)$ & 0.45 & $0.10 \pm 0.25$ \\
\hline Triglycerides & $1.5(1.1-2.1)$ & $1.5(1.1-2.0)$ & $-0.14 \pm 0.90$ & $-0.05 \pm 1.14$ & $-0.09(-0.27$ to 0.09$)$ & 0.34 & $-0.20 \pm 0.89$ \\
\hline Fasting glucose, $\mathrm{mmol} / \mathrm{L}$ & $5.9(5.4-6.7)$ & $5.9(5.4-6.6)$ & $-0.15 \pm 1.64$ & $-0.17 \pm 1.43$ & $0.01(-0.29$ to 0.30$)$ & 0.95 & $-0.19 \pm 1.63$ \\
\hline $\mathrm{HbA} 1 \mathrm{c}, \mathrm{mmol} / \mathrm{mol}$ & $40.9 \pm 12.3$ & $40.5 \pm 12.5$ & $0.41 \pm 10.10$ & $1.66 \pm 11.31$ & $-1.78(-3.77$ to 0.20$)$ & 0.08 & $0.77 \pm 9.86$ \\
\hline
\end{tabular}

Values presented as mean \pm SD or median (IQR).

BMI, body mass index; HbA1c, glycated haemoglobin; HDL-C, high-density lipoprotein cholesterol; LDL-C, low-density lipoprotein cholesterol; WW, weight loss programme.

programme directly after the baseline visit (OR 2.30) and weight loss programme participation (OR 3.33) (table 4) (model performance after internal validation: AUC $0.76, \mathrm{R}^{2} 0.24$, slope: 0.79$)$. Allocation to the intervention group significantly increased the likelihood of successful weight loss for patients with a higher age ( $\geq 65$ years; $p$ value interaction $<0.01$ ), non-smoking status ( $p$
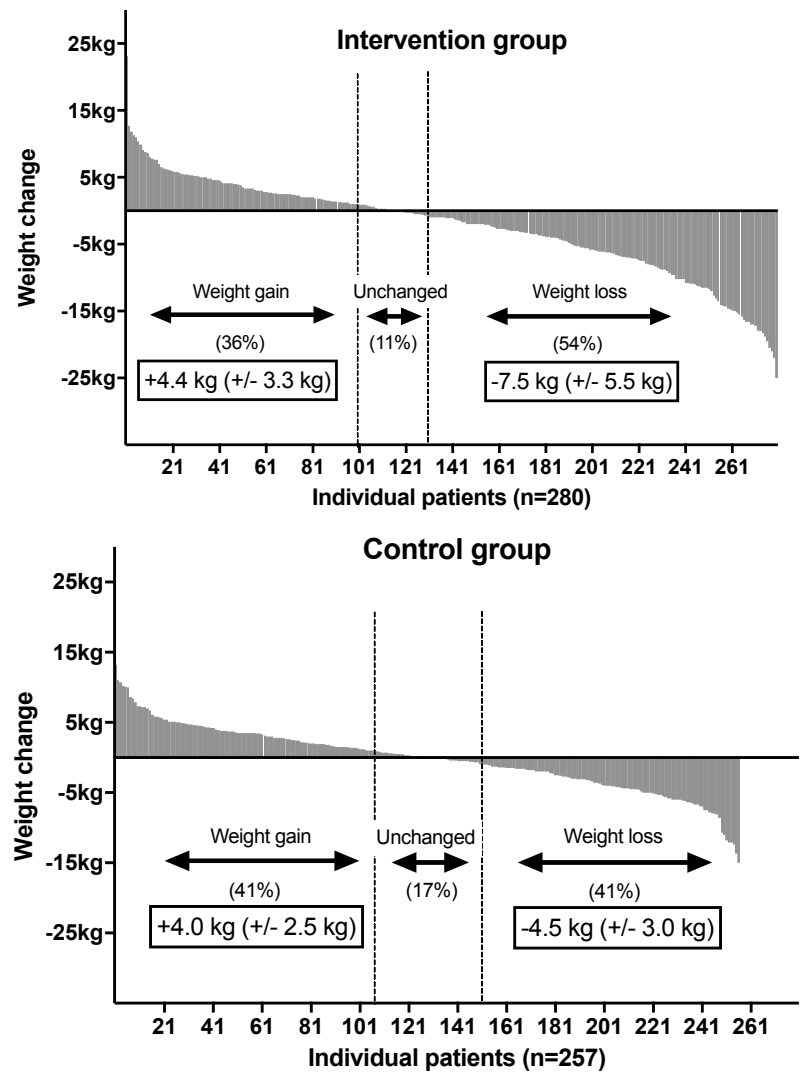

Figure 2 Waterfall plots; weight change from baseline to 12-month follow-up stratified by randomised treatment allocation. value interaction $=0.01)$ and/or motivated to lose weight ( $\mathrm{p}$ value interaction <0.001). Stratum specific effect sizes are presented in the online appendix table 5 .

Weight gain was found to be associated with five determinants in the intervention group $(n=280)$ : smoking cessation $\leq 6$ months before or during hospitalisation (OR 3.21), nonCaucasian ethnicity (OR 2.77), smoking at baseline (OR 2.70), lower age ( $<65$ years) (OR 1.47) and weight loss programme participation (OR 0.59) (table 5) (model performance after internal validation: AUC $0.77, \mathrm{R}^{2} 0.26$, slope 0.79 ). For patients smoking at baseline, and thus eligible for the smoking cessation programme, allocation to the intervention group increased the likelihood of weight gain $(p$ value interaction $<0.01$ ) (online supplemental appendix, table 5).

\section{DISCUSSION}

The main finding of our study is that in patients with CAD and overweight, referral to a community-based commercial weight loss programme as part of a comprehensive lifestyle intervention results in significantly more weight loss (mean $2.4 \pm 7.1 \mathrm{~kg}$ vs $0.2 \pm 4.6 \mathrm{~kg}, \mathrm{p}<0.001)$ as compared with usual care alone. Patients in the intervention group more often achieved clinically meaningful weight loss and attained meaningful improvements in several other CVD risk factors such as body fat percentage, waist circumference and blood pressure. In the intervention group, weight loss was associated with age over 65 years, lower educational level, non-smoking status, motivation to start with weight loss directly after the baseline visit and weight loss programme participation. A significant proportion of patients in both groups gained weight: $36 \%$ and $41 \%$ in the intervention and control group, respectively. For intervention patients, weight gain was associated with smoking cessation $\leq 6$ months before or during hospitalisation, non-Caucasian ethnicity, smoking at baseline, age under 65 years and not participating in the weight loss programme.

In line with our findings Jebb et $a l^{5}$ showed that in participants with at least one risk factor for obesity-related disease, referral by a healthcare professional to the same weight loss programme as used in our trial resulted in a mean weight loss of 
Table 3 Weight change in patients with baseline BMI $\geq 27 \mathrm{~kg} / \mathrm{m}^{2}$ from baseline to 12 -month follow-up stratified per baseline lifestyle-related risk factor group

\begin{tabular}{|c|c|c|c|c|}
\hline & $\begin{array}{l}\text { Intervention group } \\
(\mathrm{n}=280)\end{array}$ & Control group $(n=257)$ & $\begin{array}{l}\text { Between group mean difference } \\
(95 \% \mathrm{Cl})\end{array}$ & p-value \\
\hline \multicolumn{5}{|l|}{ Lifestyle-related risk factor groups } \\
\hline $\mathrm{BMI} \geq 27 \mathrm{~kg} / \mathrm{m}^{2}$ only & $-4.7 \pm 6.8$ & $-1.0 \pm 4.1$ & $-3.7(-5.6$ to -1.7$)$ & $<0.001$ \\
\hline $\mathrm{BMI} \geq 27 \mathrm{~kg} / \mathrm{m}^{2}$ and inadequate physical activity $\dagger$ & $-4.4 \pm 6.8$ & $-0.1 \pm 4.1$ & $-4.3(-5.9$ to -2.7$)$ & $<0.001$ \\
\hline $\mathrm{BMI} \geq 27 \mathrm{~kg} / \mathrm{m}^{2}$, smoking and inadequate physical activity ${ }^{\star} \dagger$ & $-0.3 \pm 6.7$ & $0.4 \pm 5.5$ & $-0.7(-2.7$ to 1.4$)$ & 0.52 \\
\hline
\end{tabular}

Weight change in $\mathrm{kg}$ presented as mean $\pm \mathrm{SD}$.

*Smoking at baseline or smoking $\leq 6$ months before hospitalisation.

tSelf-reported based on WHO recommendations.

$\mathrm{BMI}$, body mass index.

$4.1 \mathrm{~kg}( \pm 6.0)$ compared with $1.8 \mathrm{~kg}( \pm 3.8)$ in the control group. Our study adds that such a weight loss programme can also be successfully offered in patients with CAD. Though average weight lost was modest, twice as many patients in the intervention group achieved a clinically relevant weight reduction of $\geq 5 \%$ as compared with controls ( $32 \%$ vs $16 \%$; $<0.001)$.

While the relatively large number of patients who managed to lose weight in the first year after hospitalisation is encouraging, the considerable number of patients who gained weight despite being offered participation in a dedicated weight loss intervention is alarming. A weight gain in over one of three patients was seen against a background of a high level of usual care, with almost all patients (99.6\%) attending a nurse-coordinated secondary prevention programme and the majority of patients (90\%) attending cardiac rehabilitation. Prevention of weight gain may be as important as attempts to lose weight and should be an interest of future research. ${ }^{17} 18$

Weight gain in patients with CAD has been reported to be associated with factors such as age, smoking status, obesity and depression. ${ }^{19-21} \mathrm{~A}$ central factor in weight gain among CAD patients is smoking cessation. Our findings support that patients who quit smoking immediately after hospitalisation for CAD are more likely to gain weight. Surprisingly, our study found that in the intervention group, smoking at baseline was also associated with weight gain at 12 -month follow-up. Referral to the smoking cessation programme and subsequent increased smoking cessation at 12-month follow-up among intervention patients smoking at baseline compared with their control counterparts may have contributed to this finding. On average, patients who stop smoking after a myocardial infarction gain $4.8 \mathrm{~kg}( \pm 8.6)$ in

Table 4 Determinants of successful weight loss in the intervention group; candidate variables stratified by successful weight reduction ( $\geq 5 \%$ of baseline weight)

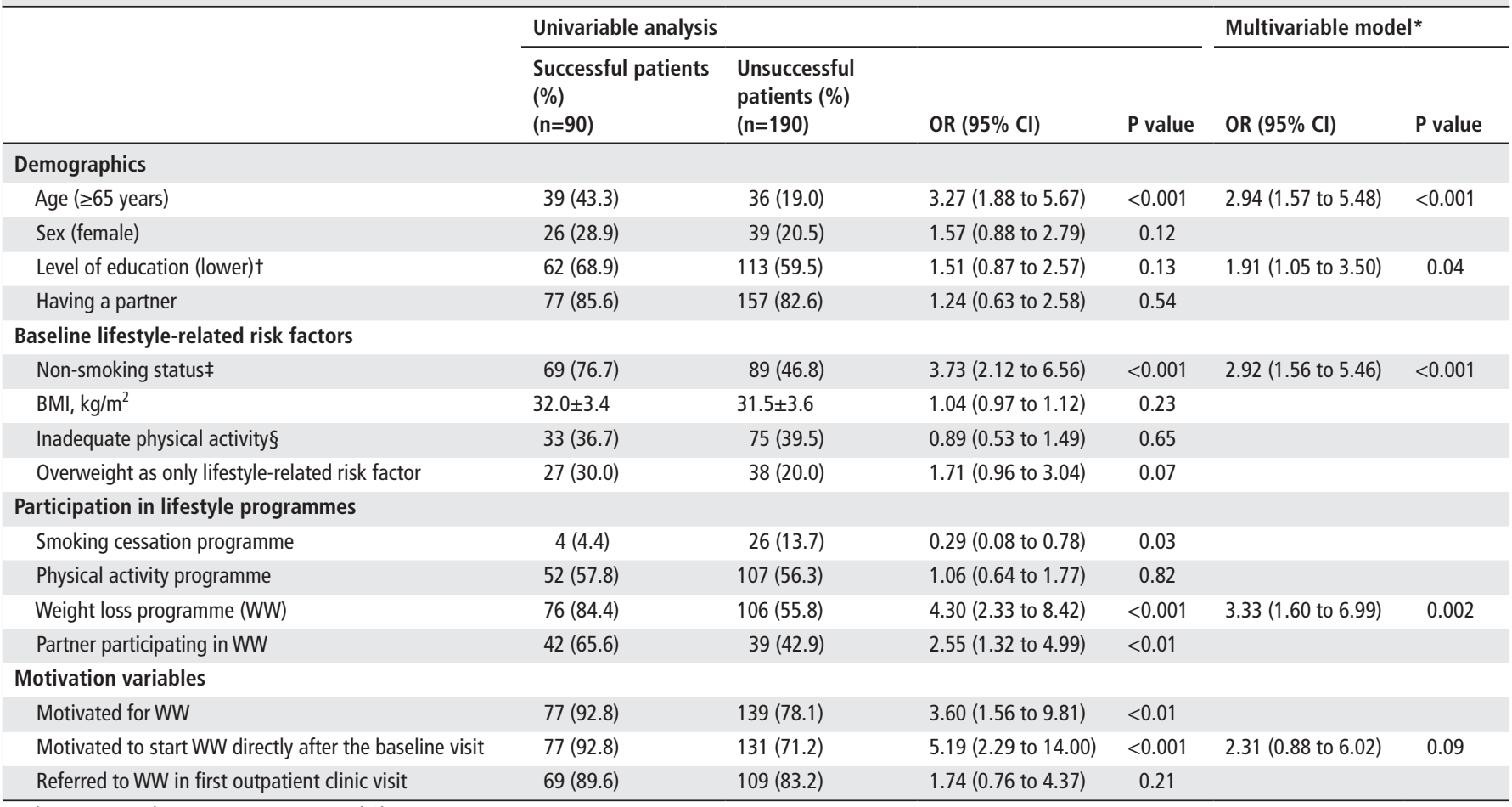

Values presented as mean+SD or counts (\%)

*Variables selected with backward elimination $(p<0.157)$ in 20 imputed datasets and estimates pooled using Rubins' rule.

tLower education: all except universities of applied sciences and research universities.

¥Never smoking or quit $>6$ months before hospitalisation.

$\S$ Self-reported based on WHO recommendations.

BMI, body mass index. 
Table 5 Determinants of weight gain in the intervention group; candidate variables stratified by weight gain ( $\geq 1 \mathrm{~kg}$ of baseline weight)

\begin{tabular}{|c|c|c|c|c|c|c|}
\hline & \multicolumn{4}{|l|}{ Univariable analysis } & \multicolumn{2}{|c|}{ Multivariable model* } \\
\hline & $\begin{array}{l}\text { Weight gain }(\geq 1 \mathrm{~kg}) \\
(\mathrm{n}=100)\end{array}$ & $\begin{array}{l}\text { No weight gain } \\
(n=180)\end{array}$ & OR $(95 \% \mathrm{Cl})$ & $P$ value & OR $(95 \% \mathrm{Cl})$ & $P$ value \\
\hline \multicolumn{7}{|l|}{ Demographics } \\
\hline Age (<65 years) & $81(81.0)$ & $124(68.9)$ & 1.93 (1.08 to 3.54$)$ & 0.03 & 1.47 (0.78 to 2.78$)$ & 0.23 \\
\hline Sex (female) & $20(20.0)$ & $45(25.0)$ & 0.75 (0.41 to 1.34$)$ & 0.34 & & \\
\hline Ethnicity (non-Caucasian) & $10(10.0)$ & $6(3.3)$ & $3.22(1.16$ to 9.74$)$ & 0.03 & 2.77 (0.90 to 8.55$)$ & 0.08 \\
\hline Level of education (lower) $\dagger$ & $62(62.0)$ & $113(62.8)$ & 0.97 (0.59 to 1.61$)$ & 0.90 & & \\
\hline Having a partner & $83(83.0)$ & $151(83.9)$ & 0.94 (0.49 to 1.84$)$ & 0.85 & & \\
\hline \multicolumn{7}{|l|}{ Baseline lifestyle-related risk factors } \\
\hline \multicolumn{7}{|l|}{ Smoking } \\
\hline Smoking at baseline $\ddagger$ & $29(29.0)$ & $28(15.6)$ & 2.22 (1.23 to 4.02$)$ & 0.01 & $2.70(1.38$ to 5.27$)$ & 0.004 \\
\hline Quit smoking before or during hospitalisation§ & $34(34.0)$ & $31(17.2)$ & 2.48 (1.41 to 4.38$)$ & $<0.01$ & 3.21 (1.70 to 6.08$)$ & $<0.001$ \\
\hline $\mathrm{BMI}, \mathrm{kg} / \mathrm{m}^{2}$ & $31.5 \pm 4.0$ & $31.7 \pm 3.3$ & $0.98(0.91$ to 1.05$)$ & 0.62 & & \\
\hline Inadequate physical activity & $63(63.0)$ & $109(60.6)$ & 1.11 (0.67 to 1.85$)$ & 0.69 & & \\
\hline Established diabetes mellitus type 2 & $16(16.0)$ & $32(17.8)$ & $0.88(0.45$ to 1.68$)$ & 0.71 & & \\
\hline \multicolumn{7}{|l|}{ Participation in lifestyle programmes } \\
\hline Smoking cessation & $16(16.0)$ & $14(7.8)$ & 2.26 (1.05 to 4.91$)$ & 0.04 & & \\
\hline Physical activity & $49(49.0)$ & $110(61.1)$ & $0.61(0.37$ to 1.00$)$ & 0.05 & & \\
\hline Weight loss & $54(54.0)$ & $128(71.1)$ & $0.48(0.29$ to 0.79$)$ & $<0.01$ & 0.59 (0.34 to 1.02$)$ & 0.06 \\
\hline Partner participating in WW & $21(44.7)$ & $60(55.6)$ & 0.65 (0.32 to 1.28$)$ & 0.21 & & \\
\hline Motivated for WW & 75 (78.9) & $141(84.9)$ & $0.66(0.35$ to 1.29$)$ & 0.22 & & \\
\hline
\end{tabular}

Values presented as mean \pm SD or counts $(\%)$.

*Variables selected with backward elimination ( $\mathrm{pp}<0157)$ in 20 imputed datasets and estimates pooled using Rubins' rule.

tLower education: all except universities of applied sciences and research universities.

¥Baseline urine-cotinine level $>200 \mathrm{ng} / \mathrm{mL}$.

$\S$ Smoking cessation $\leq 6$ months before or during hospitalisation.

ๆSelf-reported based on WHO recommendations.

BMI, body mass index; WW, weight loss programme.

the first year. ${ }^{22}$ Our analysis in patients with a BMI $\geq 27 \mathrm{~kg} / \mathrm{m}^{2}$ found less pronounced weight gain in patients who successfully quit smoking at 12 -month follow-up $(+0.9 \pm 7.4 \mathrm{~kg}$ in interventions vs $+1.8 \pm 5.2 \mathrm{~kg}$ in controls, $\mathrm{p}=0.16)$. Participation in a weight loss or physical activity programme may have attenuated weight gain associated with smoking cessation.

Five determinants were found to be associated with achieving successful weight loss in the intervention group. Although older age is generally associated with weight gain, our findings are in line with previous reports that observed higher age as an important determinant for dietary adherence and weight loss in lifestyle interventions. ${ }^{23}{ }^{24}$ Intended weight loss through dieting and exercise can greatly improve health-related quality of life in elderly CAD patients. ${ }^{25}$ Unintended weight loss, however, can be a sign of underlying pathology or deconditioning and should prompt appropriate investigations. A lower educational level was, after adjustment for smoking status, significantly associated with a higher chance of successful weight loss. Consistent with previous reports that identified autonomous motivation as an important factor in sustaining lifestyle improvements, motivation to start with weight loss directly after the baseline visit was strongly associated with successful weight loss. ${ }^{26}$ Finally, a nonsmoking status and attending the weight loss intervention were the strongest determinants of successful weight loss.

These determinants of weight change represent statistical associations and could potentially assist clinicians and researchers in further developing weight loss programmes in patients with CAD. Hypothetically, when tailoring such programmes, selecting patients based on one or more of these determinants could lead to a more cost-effective approach with higher success rates (figure 3). While both the American College of Cardiology and ESC guidelines recommend personalised secondary prevention, ${ }^{89}$ recommendations on how to implement this are lacking. Our findings show determinants that could be of use to personalise weight loss interventions.

\section{Strengths and limitations}

There are several strengths to our study. First, our study investigated a highly practical approach, using widely available lifestyle interventions, without modifications, which facilitates implementation of these programmes into daily practice. Second, compared with other weight loss trials, our study had little loss to follow-up, ${ }^{5} 27$ which we thoroughly evaluated. Finally, the multivariable regression analysis provides insights in achieving meaningful weight loss in overweight CAD patients and can potentially assist in further personalisation of weight loss programmes.

Some aspects of our study merit consideration. First, we used a subgroup of patients from the original randomised trial, because of which comparability between treatment arms cannot be fully guaranteed. Second, we excluded patients with depressive symptoms, congestive heart failure, a language barrier or without internet access. Potentially, these individuals represent patients with a lower socioeconomic status, who are in particular need of optimal secondary prevention. ${ }^{28}$ Third, to evaluate long-term impact on prognosis, a longer follow-up period is necessary. Most studies evaluating weight loss programmes report positive results for short term ( $\leq 12$ months) but limited or conflicting results for intermediate or long-term follow-up ( $\geq 24$ months). ${ }^{29} 30$ We are currently collecting long-term follow-up data of the RESPONSE-2 trial. Finally, our analyses of determinants of weight change should 


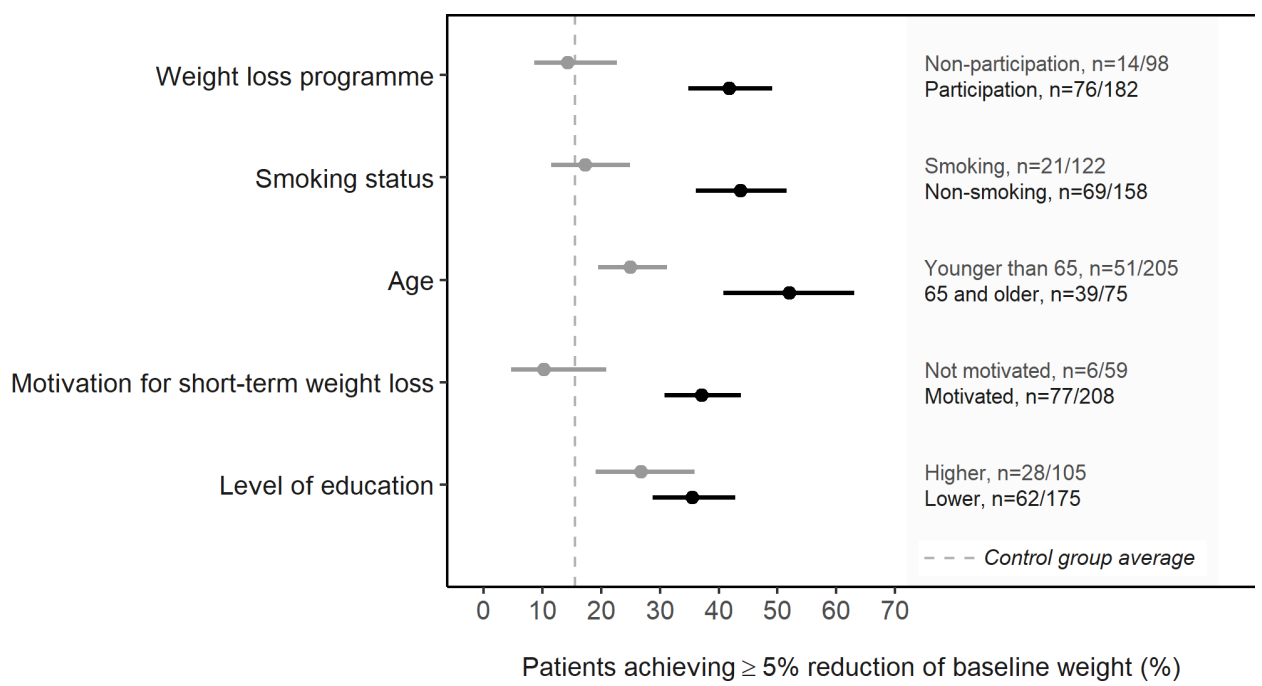

Figure 3 Percentage of intervention group patients achieving successful weight loss at the 12-month follow-up, stratified per determinants of successful weight loss.

be interpreted with caution. Though we used extensive resampling methods, data-driven variable selection is susceptible to overfitting. In new populations, these models may perform less well and external validation is advised.

\section{CONCLUSION}

Our highly practical approach of nurse-coordinated referral to a community-based weight loss intervention, as part of a

\section{Key messages}

\section{What is already known on this subject?}

- In patients with obesity and cardiovascular disease, weight loss of $5 \%-10 \%$ can significantly reduce lifetime risk of recurrent events. As cardiac rehabilitation alone is insufficient to achieve meaningful weight loss, there is a need for effective, targeted weight loss strategies.

\section{What might this study add?}

- Referral to a commercial weight loss intervention, as part of a secondary prevention programme, leads to significantly more weight loss on average at 12-month follow-up than usual care alone in patients with cardiovascular disease $(-2.4 \mathrm{~kg}$ vs $-0.2 \mathrm{~kg}$ ). In the intervention group, determinants of $\geq 5 \%$ reduction of baseline weight were higher age, lower level of education, non-smoking status, motivation to start with weight loss directly after the baseline visit and attending the weight loss intervention. On average, patients who successfully quit smoking in the intervention group gained less weight through the combined lifestyle intervention than patients who quit smoking in the control group.

\section{How might this impact on clinical practice?}

- Referral to a commercial weight loss programme as part of a comprehensive strategy increases the likelihood of achieving meaningful weight loss in patients with coronary artery disease and overweight. Potentially, tailoring weight management strategies to patient characteristics associated with meaningful weight loss can lead to a more cost-effective approach and higher success rates. comprehensive secondary prevention strategy, leads to significantly increased rates of weight loss in CAD patients with overweight. Alarmingly, weight gain was highly prevalent, and prevention of weight gain may be as important as attempts at weight loss. The identified determinants of weight change may contribute to further development of effective weight management strategies.

Acknowledgements We are grateful to the members of the Randomised Evaluation of Secondary Prevention by Outpatient Nurse SpEcialists-2 (RESPONSE-2) study group, all patients participating in the RESPONSE-2 study and the contribution of all research nurses.

Contributors MM, SL, MS, HTJ, WSoR and RJP participated in the design of the study. MM, SL and MS were responsible for the coordination and acquisition of the data. AT, MM, SL, MS and HTJ performed the statistical analysis. All authors contributed to the preparation, critical review and approved the final manuscript.

Funding The RESPONSE-2 trial was sponsored by WW International Inc (formerly Weight Watchers International, Inc) (New York, New York, USA), Philips Consumer Lifestyle (Eindhoven, the Netherlands) and an anonymous private fund (Amsterdam, the Netherlands).

Disclaimer AT, MM, SL, MS, HTJ and WJMSR: none reported. RJP reported personal fees from Sanofi Aventis, Boehringer Ingelheim, Amgen and from AstraZeneca, outside the submitted work. The sponsors had no role in the design, data collection, data analysis, data interpretation and writing of the manuscript.

Competing interests None declared.

Patient consent for publication Not required.

Ethics approval The institutional committees on human research of all recruiting hospitals approved the protocol (METC 2012_272; Netherlands Trial Registry: NTR3937), and written informed consent was obtained from all patients.

Provenance and peer review Not commissioned; externally peer reviewed.

Data availability statement Data are available on reasonable request. Requests for analyses of deidentified data from this trial should be directed to: M Snaterse ( $\mathrm{m}$. snaterse@hva.nl).

Supplemental material This content has been supplied by the author(s). It has not been vetted by BMJ Publishing Group Limited (BMJ) and may not have been peer-reviewed. Any opinions or recommendations discussed are solely those of the author(s) and are not endorsed by BMJ. BMJ disclaims all liability and responsibility arising from any reliance placed on the content. Where the content includes any translated material, BMJ does not warrant the accuracy and reliability of the translations (including but not limited to local regulations, clinical guidelines, terminology, drug names and drug dosages), and is not responsible for any error and/or omissions arising from translation and adaptation or otherwise.

ORCID iD

Marjolein Snaterse http://orcid.org/0000-0002-4923-6845 


\section{REFERENCES}

1 Kotseva K, Wood D, De Bacquer D, et al. EUROASPIRE IV: a European Society of cardiology survey on the lifestyle, risk factor and therapeutic management of coronary patients from 24 European countries. Eur J Prev Cardio/ 2016;23:636-48.

2 Klein S, Burke LE, Bray GA, et al. Clinical implications of obesity with specific focus on cardiovascular disease: a statement for professionals from the American heart association Council on nutrition, physical activity, and metabolism: endorsed by the American College of cardiology Foundation. Circulation 2004;110:2952-67.

3 Knowler WC, Barrett-Connor E, Fowler SE, et al. Reduction in the incidence of type 2 diabetes with lifestyle intervention or metformin. N Engl J Med 2002;346:393-403.

4 Franz MJ, VanWormer JJ, Crain AL, et al. Weight-Loss outcomes: a systematic review and meta-analysis of weight-loss clinical trials with a minimum 1-year follow-up. J Am Diet Assoc 2007;107:1755-67.

5 Jebb SA, Ahern AL, Olson AD, et al. Primary care referral to a commercial provider for weight loss treatment versus standard care: a randomised controlled trial. Lancet 2011;378:1485-92.

6 Minneboo M, Lachman S, Snaterse M, et al. Community-Based lifestyle intervention in patients with coronary artery disease: the RESPONSE-2 trial. J Am Coll Cardiol 2017;70:318-27.

7 Lachman S, Minneboo M, Snaterse M, et al. Community-Based comprehensive lifestyle programs in patients with coronary artery disease: objectives, design and expected results of randomized evaluation of secondary prevention by outpatient nurse specialists 2 trial (response 2). Am Heart J 2015;170:216-22.

8 Piepoli MF. European guidelines on cardiovascular disease prevention in clinical practice. Eur Heart J 2016:2016:2315-81.

9 Eckel RH, John Jakicic C-CM, Jamy Ard C-CD. 2013 AHA/ACC guideline on lifestyle management to reduce cardiovascular risk: a report of the American College of Cardiology/American heart association Task force on practice guidelines. JAC 2014;63:2960-84.

10 Tjin-A-Ton JJS, Konings KTS. Herziene richtlijn 'Cardiovasculair risicomanagement' [Revision Dutch Guideline Cardiovascular Disease Prevention 2019]. Ned Tijdschr Geneeskd 2019;163:D4237.

11 Jorstad HT, Chan YK, Scholte op Reimer WJM, et al. Nurses' perspectives on nursecoordinated prevention programmes in secondary prevention of cardiovascular disease: a pilot survey. Contemp Nurse 2015;51:96-106.

12 Beatty AL, Schiller NB, Whooley MA. Six-minute walk test as a prognostic tool in stable coronary heart disease: data from the heart and soul study. Arch Intern Med 2012:172:1096-102.

13 Bellet RN, Adams L, Morris NR. The 6-minute walk test in outpatient cardiac rehabilitation: validity, reliability and responsiveness - a systematic review. Physiotherapy 2012;98:277-86.

14 Carpenter JR, Kenward MG. Multiple imputation and its application. 1st edn. John Wiley \& Sons, Ltd, 2013.
15 Sauerbrei $W$. The use of resampling methods to simplify regression models in medical statistics. J R Statist Soc C 1999;48:313-29.

16 Heymans MW. Multiple Imputation and Bootstrapping - Method boot_MI • psfmi. Available: https://mwheymans.github.io/psfmi/articles/boot_Ml.html [Accessed 28 May 2021].

17 Ulian MD, Aburad L, da Silva Oliveira MS, et al. Effects of health at every size ${ }^{\circledR}$ interventions on health-related outcomes of people with overweight and obesity: a systematic review. Obes Rev 2018;19:1659-66.

18 Bennett GG, Foley P, Levine E, et al. Behavioral treatment for weight gain prevention among black women in primary care practice: a randomized clinical trial. JAMA Intern Med 2013;173:1770-7

19 Fadl YY, Krumholz HM, Kosiborod M, et al. Predictors of weight change in overweight patients with myocardial infarction. Am Heart J 2007;154:711-7.

20 van Dieren S, Czernichow S, Chalmers J, et al. Weight changes and their predictors amongst 11140 patients with type 2 diabetes in the advance trial. Diabetes Obes Metab 2012;14:464-9.

21 Snaterse M, Jorstad HT, Minneboo M, et al. Smoking cessation after nursecoordinated referral to a comprehensive lifestyle programme in patients with coronary artery disease: a substudy of the RESPONSE-2 trial. Eur J Cardiovasc Nurs 2019;18:113-21.

22 Dehghani P, Habib B, Windle SB, et al. Smokers and Postcessation weight gain after acute coronary syndrome. J Am Heart Assoc 2017;6. doi:10.1161/JAHA.116.004785. [Epub ahead of print: 18 Apr 2017].

23 Ades PA, Savage PD, Harvey-Berino J. The treatment of obesity in cardiac rehabilitation. J Cardiopulm Rehabil Prev 2010;30:289-98.

24 Jepma P, Jorstad HT, Snaterse M, et al. Lifestyle modification in older versus younger patients with coronary artery disease. Heart 2020;106:1066-72.

25 Ades PA, Savage PD. Potential benefits of weight loss in coronary heart disease. Prog Cardiovasc Dis 2014;56:448-56.

26 Peterson JC, Allegrante JP, Pirraglia PA, et al. Living with heart disease after angioplasty: a qualitative study of patients who have been successful or unsuccessful in multiple behavior change. Heart Lung 2010;39:105-15.

27 Ross HM, Laws R, Reckless J, et al. Evaluation of the Counterweight programme for obesity management in primary care: a starting point for continuous improvement. $\mathrm{Br}$ J Gen Pract 2008;58:548-54.

28 Murphy A, Palafox B, O'Donnell O, et al. Inequalities in the use of secondary prevention of cardiovascular disease by socioeconomic status: evidence from the pure observational study. Lancet Glob Health 2018;6:e292-301.

29 Gudzune KA, Doshi RS, Mehta AK, et al. Efficacy of commercial weight-loss programs: an updated systematic review. Ann Intern Med 2015;162:501-12.

30 Atallah R, Filion KB, Wakil SM, et al. Long-Term effects of 4 popular diets on weight loss and cardiovascular risk factors: a systematic review of randomized controlled trials. Circ Cardiovasc Qual Outcomes 2014;7:815-27. 